\title{
A BLOCKCHAIN AND SMART CONTRACT-BASED FRAMEWORK TO INCREASE TRACEABILITY OF BUILT ASSETS
}

\author{
Jennifer $\mathrm{Li}^{1}$, Mohamad Kassem ${ }^{2}$, and Richard Watson ${ }^{3}$
}

\begin{abstract}
The UK Government's review of Building Regulations and Fire Safety 2018 identified a series of failings in the construction sector including ambiguous and inconsistent regulations and standards; lack of clarity of roles and responsibilities; lack of enforcement of regulations and standards; poor product testing, labelling and marketing; inconsistent competency across the sector; and failure to address building occupants' concerns around health and safety. Traceability and the development of a digital record to provide a golden thread of information were two recommendations of the report. To address these recommendations, this paper considered the extent to which the integration of Building Information Modelling (BIM), distributed ledger technology (DLT), the Internet of Things (IoT) and smart contracts in the form of a decentralised autonomous organisation (DAO) can support enhanced traceability and the population and management of a digital record during the building maintenance phase as part of a solution to provide a platform for the digital record. A framework is proposed to bring these technological systems together creating an ecosystem that encourages digitalisation and provides traceability, better information management and compliance with regulations and standards. Further work will involve testing the framework by simulating a range of maintenance events.
\end{abstract}

Keywords: construction, digital record, distributed ledger technology (DLT), smart contracts, traceability.

\section{INTRODUCTION}

There were two key recommendations that came out of the UK Governmentcommissioned review on Building Regulations and Fire Safety (Hackitt, 2018) (herein referred to as the Hackitt Report) - the need for far greater traceability and a digital record to provide the golden thread of information. Traceability is concerned with the products and materials that go into buildings regarding the ability to trace those products and materials from provenance throughout their lifecycle. Adapted from Olsen and Borit (2018), traceability is defined as, "The ability to access all required information relating to that which is under consideration, throughout its entire lifecycle, by means of recorded identifications" (Watson et al., 2019, p. 498). A digital record to provide the golden thread of information is about producing and recording good quality information of a building from initial design intent to the current as-built state. This includes any

$1 \quad$ PhD Candidate, Department of Mechanical Engineering \& Construction, Faculty of Engineering \& Environment, Northumbria University, Newcastle, UK, Jennifer.Li@northumbria.ac.uk

2 Associate Professor, Department of Mechanical Engineering \& Construction, Faculty of Engineering \& Environment, Northumbria University, Newcastle, UK, Mohamad.Kassem@northumbria.ac.uk

3 Senior Lecturer, Department of Architecture \& Built Environment, Faculty of Engineering \& Environment, Northumbria University, Newcastle, UK, Richard.Watson@northumbria.ac.uk 
decisions and changes made throughout the asset lifecycle to allow for better and safer management of that building. Recommendation 8.1 of the Hackitt Report proposes, "Government should mandate a digital (by default) standard of record-keeping for the design, construction and during the occupation of new [higher-risk residential buildings] HRRBs. This is to include any subsequent refurbishments within those buildings" (Hackitt, 2018, p. 104).

The Hackitt Report revealed a series of failings of the construction sector. While this is far from an exhaustive list of construction sector failings (see, for example, Farmer (2016) and Woodhead et al., (2018)), these are the failings that prompted the proposal of a mandate (Hackitt, 2018, p. 3):

1. the roles and responsibilities of those procuring, designing, constructing and maintaining buildings are unclear;

2. the package of regulations and guidance (in the form of Approved Documents) can be ambiguous and inconsistent;

3. the processes that drive compliance with building safety requirements are weak and complex with poor record keeping and change control in too many cases;

4. competence across the system is patchy;

5. the product testing, labelling and marketing regime is opaque and insufficient; and

6. the voices of residents often goes [sic] unheard, even when safety issues are identified.

These result from of lack of ability to enforce regulations and standards, fragmented processes and systems that do not ensure the health and safety of building occupants, and ambiguity and inconsistencies in documentation and roles and responsibilities.

The ability to ensure availability and access to the right information in the right format at the right time is crucial to successful operations of the construction sector. Information quality is as important as information traceability as it is the available information that drives decision-making. Raymond and Bergeron (2008) measure information quality using six items: availability, relevance, reliability, precision, comprehensiveness, and security. Jylhä and Suvanto opine that, "if the information is poor, the actions that are based on the information are also wrong and thus have a negative impact on the value creation process" (2015, p. 304).

The Hackitt Report that was commissioned by HM Government in response to poor quality building renovations resulting in the Grenfell Tower fire in 2017 and the 72 deaths that followed (Rice-Oxley, 2018). In addition, Christiansen (2018) identified four challenges to building maintenance as controlling costs (e.g. for energy, services, maintenance), good record keeping and data analysis, emergency response and safety, and extending the life of the asset. This study aims to consider the extent to which emerging technologies (blockchain, smart contracts and the Internet of Things) can support enhanced traceability and the population and management of a digital record during the building maintenance phase as part of a solution to provide a platform for the digital record. A framework is proposed for semi-automated maintenance and repairs of built assets during the operation stage of the lifecycle based on integration between Building Information Modelling (BIM), Internet of Things (IoT), distributed ledger technology (DLT) and smart contracts to address these problems.

Section 2 describes the technological systems considered in this paper; section 3 presents the current state of traceability in the construction sector; section 4 proposes a 
framework for semi-automation of maintenance and repairs during the operation of built assets; and sections 5 and 6 provide discussion and conclusions respectively.

\section{TECHNOLOGicAl Systems FoR THE CONSTRUCTION SECTOR}

The technological systems discussed in this paper integrate to create an ecosystem that encourages traceability and better record keeping of products, services and activities that take place across the built asset lifecycle. In this context, they are conceived as "socially constructed and society shaping systems" consisting of "physical artefacts; organisations; scientific components and legislative artefacts" (van Dam, 2019, pp. 4-5). This section considers the physical artefacts as built assets equipped with sensors to provide real-time data of its conditions and the scientific components as the different information technology (IT) systems that integrate to provide an ecosystem for automated maintenance and repair activities. Organisations and legislative artefacts are considered alongside presentation of the proposed framework in section 4 .

\subsection{Distributed ledger technology (DLT)}

DLT such as Blockchain, the underlying technology for the first successful cryptocurrency-Bitcoin, is a system that offers immutable and secure processing and recording of transactions that can be anything of value across a distributed, decentralised, peer-to-peer network (Li et al., 2019a). Several types of DLT are available including public, consortium and private; access can be permissioned or permissionless (Allison and Warren, 2019). DLT offers a potential storage mechanism for a digital record as proposed by the Hackitt Report and can support wider historical record keeping of built assets throughout the lifecycle.

\subsection{Smart contracts and decentralised autonomous organisations (DAOs)}

Smart contracts are pieces of computer code built on the if/then principle that selfexecute and self-enforce based on pre-defined objectives and parameters (Clack et al., 2016). They can be used to increase efficiencies and traceability (Penzes, 2018). In a previous study, DLT and smart contracts were identified as drivers for new business models and organisational structures ( $\mathrm{Li}$ et al., 2019a). One such structure is a decentralised autonomous organisation (DAO), which is an entity not managed by any one individual but by consensus of the parties setting up the DAO. Power is determined by merit calculated according to the number of tokens owned by a party and the level of trust they have within the network (Van Rijmenam and Schweitzer, 2018). A DAO is a collection of smart contracts that cannot be altered once deployed and will always operate as programmed. Therefore, ensuring the smart contracts that make up the DAO are compliant with regulations and function as intended is essential as they cannot be "turned off" once executed. Smart contracts offer the ability to automate tasks and activities throughout the built asset lifecycle whilst also acting as a mechanism to enforce compliance with regulations. The benefits of DAOs include disintermediation "under the premise that knowledge assets are codifiable and can be automated" (Sreckovic and Windsperger, 2019, p. 847), they can reduce running costs and transfer risk.

Morabito (2017) describes two types of smart contracts - deterministic and nondeterministic. A deterministic smart contract requires only the information already provided on a distributed ledger to execute (i.e. no external or additional information is required); a non-deterministic smart contract requires additional information from a 
trusted third party. While an aspect of DLT and smart contracts is the goal of reducing the need for intermediaries, or third parties (Li et al., 2019a), these do not need to come from human intermediaries as is often the case in the current ecosystem. This outside party is called an "oracle" and IoT-enabled devices can fulfil this capacity as is discussed in the following sub-section.

\subsection{Internet of Things (IoT)}

The interconnection of everyday objects via the use of sensors and internet connectivity is termed the Internet of Things (IoT). IoT-enabled devices are able to communicate with each other without the need for human interaction (Barnaghi et al., 2012). IoT is supporting the move toward automated systems through "the common conception of things that are identifiable, readable, controllable, addressable, and locatable via the Internet" (Pirbhulal et al., 2017, p. 1). IoT can provide part of the information required for a digital record for some products (particularly building services components and systems) through their use as oracles. For example, if a heating, ventilation and air conditioning (HVAC) unit has a problem and it is equipped with an IoT sensor, the sensor will collect data about the unit's problem and inform a smart contract that it requires servicing. The IoT sensor acts as an oracle providing the smart contract with only the necessary data needed to make arrangements for servicing.

\subsection{Building Information Modelling (BIM)}

The UK Government is driving the sector to adopt BIM to achieve better management of information across construction projects (UK BIM Framework, 2020). BIM is defined by BS EN ISO 19650-1 as the "use of a shared digital representation of a built asset to facilitate design, construction and operation processes to form a reliable basis for decisions" (ISO, 2018, p. 5). BIM is the de facto method of managing construction projects across the built asset lifecycle, which requires a significant push to digitalise current practices across the construction sector to enable effective information sharing and collaboration where all stakeholders contribute to an "information model" continuously throughout the asset's lifecycle.

There is evidence of adoption of BIM during the design and construction phases, however, use of BIM at the operation phase of the asset lifecycle is sparse (Ghaffarianhoseini et al., 2017; Aslam and Tarmizi, 2018). The reasons for this include: organisations are reluctant to share information that is perceived as intellectual property or competitive advantage (Jylhä and Suvanto, 2015); organisations are using different software programmes raising issues of interoperability between project participants (Ghaffarianhoseini et al., 2017); use of BIM on a construction site is limited due to lack of content in the information models, lack of on-site mobile technology and lack of trained personnel (Mäki and Kerosuo, 2015); and once handover has taken place, asset owners and/or facilities managers are failing to continue using the information model with information quality cited as a key reason for this (Naghshbandi, 2016). Where work is carried out as part of maintenance and repairs of a built asset, invariably, reports, guarantees, warranties and invoices are paper based making long-term storage an issue, often with no back-up in digital form.

Each of these systems, either individually or through integration, can provide support to addressing some of the six challenges laid out by the Hackitt Report and stated above. For failing 1, implementation of smart contracts in the form of a DAO will force roles and responsibilities to be made explicit, particularly as ISO 19650 is clear in terms of 
roles and responsibilities for the delivery and management of building information. In addition, DLT as an immutable record has potential to drive "good behaviour". Failing 2 requires unambiguous and consistent regulations and guidance; smart contracts will require clear and concise regulations to enable effective coding and self-execution. DLT will drive better record keeping And smart contracts can support stronger compliance to ensure processes are brought in line with building safety requirements from failing 3. Failings 4 and 5 are addressed in section 4 and while the proposed framework will not address the issue around the voices of residents going unheard, failing 6, plans are in place to address this through the government's response to the findings of the Hackitt Report (Ministry of Housing, Communities and Local Government, 2020).

\section{TRACEABILITY AND THE Digital RECORD}

Katenbayeva (2016) discusses the challenges of defining traceability for the sector where many definitions focus on tracking goods through a supply chain resulting in definitions on provenance and chain of custody through delivery. With lack of information traceability a key aspect of the Hackitt Report, current research on traceability at the operation stage of the built asset lifecycle is sparse. Lee et al., (2017) design Kaohsiung City Building Construction Traceability System that collects data regarding building inspections during construction to make it public for use in the event of earthquakes. However, the research is focused on the user interface of an internet-based service rather than addressing the issue of traceability in construction. Pinti et al., (2018) explore the integration of BIM and facilities management (FM) focusing on data collection, interoperable data exchange and collaboration during operation and maintenance of public administration buildings to support better information management and decisionmaking.

The amount of data produced during the lifecycle of a built asset is vast; currently, $96 \%$ of data goes unused and 13\% of working time is spent searching for information (Snyder et al., 2018). Construction firm, FARO, has developed the concept of 'Traceable Construction' that brings together new and existing technologies to create an ecosystem that captures and processes data across the lifecycle of a built asset (FARO, 2019). Tata Steel is piloting a "traceable chain of custody" from raw material state to in-use following the life of a steel beam until it is reused or recycled (Penzes, 2018, p. 31). During the pilot, Tata Steel made data relating to the beam 'available upon request' rather than available in the public domain but each individual beam will be given a unique ID and tracked on a blockchain. Halcyon, a digital collaboration platform from Kraken IM is a world-first in blockchain-based information management that allows stakeholders to "supply, validate and approve engineering data then creates an immutable record of that data" providing "a permanent digital golden thread of the information, decisions and queries made during projects" (Kraken IM, 2020).

While much existing literature on traceability is concerned with supply chain and logistics (Katenbayeva , 2016), to encompass that which is addressed in the Hackitt Report, this study also considers traceability to include information about changes from the initial design intent to as-built state (e.g. rationale and decision-maker), manufacturer information about building components (e.g. HVAC units), installation information (e.g. when it was installed, by whom, any problems that arose during installation), scheduled maintenance and repairs/replacements (e.g. when, by whom, the process followed, any problems that arose etc.), and renovations and refurbishments. 
In addition, a comprehensive definition for a digital record was devised, forthwith adapted to include services: " $A$ digital record provides traceability through a secure, immutable and auditable electronic record of all required information, actions and decisions taken to assess and achieve compliance of a built asset with relevant standards and regulations at a point in time. It must record stakeholder and compliance requirements, design intent, procurement of materials/components/services and construction together with the testing, validation and verification processes undertaken, capturing their outcomes in order to provide a complete decision-trail. The record will include physical asset and performance data of all components and support traceability of provenance from raw material state through manufacturing, installation, maintenance and disposal, detailing who did what, when, why, how and to what specification. The digital record must be accurate, traceable, appropriately open, non-proprietary, searchable, and show clear delineations of risk ownership" (Watson et al., 2019, p. 498). Having the right data available can improve management, decision making and operational effectiveness; better procurement practices through increased traceability; faster response to health and safety issues; and more effective product recall.

\section{A Proposed Framework For SEMI-Automated MAINTENANCE AND REPAIRS OF BUILT ASSETS DURING OPERATION}

To address many of the problems raised in the Hackitt Report and Christinasen (2018) above, this study proposes the integration of BIM, IoT, DLT and smart contracts to automate existing processes during the operation and maintenance phase whilst simultaneously creating digital information from the outset. Automation, and production and recording of digital information will increase traceability of information for built assets at the operation phase and allow automated compilation of a proposed digital record. This integration of systems and technologies is built on the foundation proposed in Li et al., (2019b). This study extends that approach by conceptualising semiautomation of maintenance and repairs of an operational asset. Figure 1 visualises the steps taken in the semi-automated process and conceptualises how the different technological systems integrate.

The "Physical Asset" represents any built asset to which this framework could be applied. Components that make up building services systems within the built asset are fitted with IoT sensors that can detect abnormal behaviour and send a signal to the "CAFM" system. To ensure security of the process, the "DAO" is conceptualised as running on a distributed ledger, specifically, the Blockchain protocol (i.e. a linear, append only distributed ledger). The "e-Marketplace" is an automated web-based portal for managing tenders for organisations. 


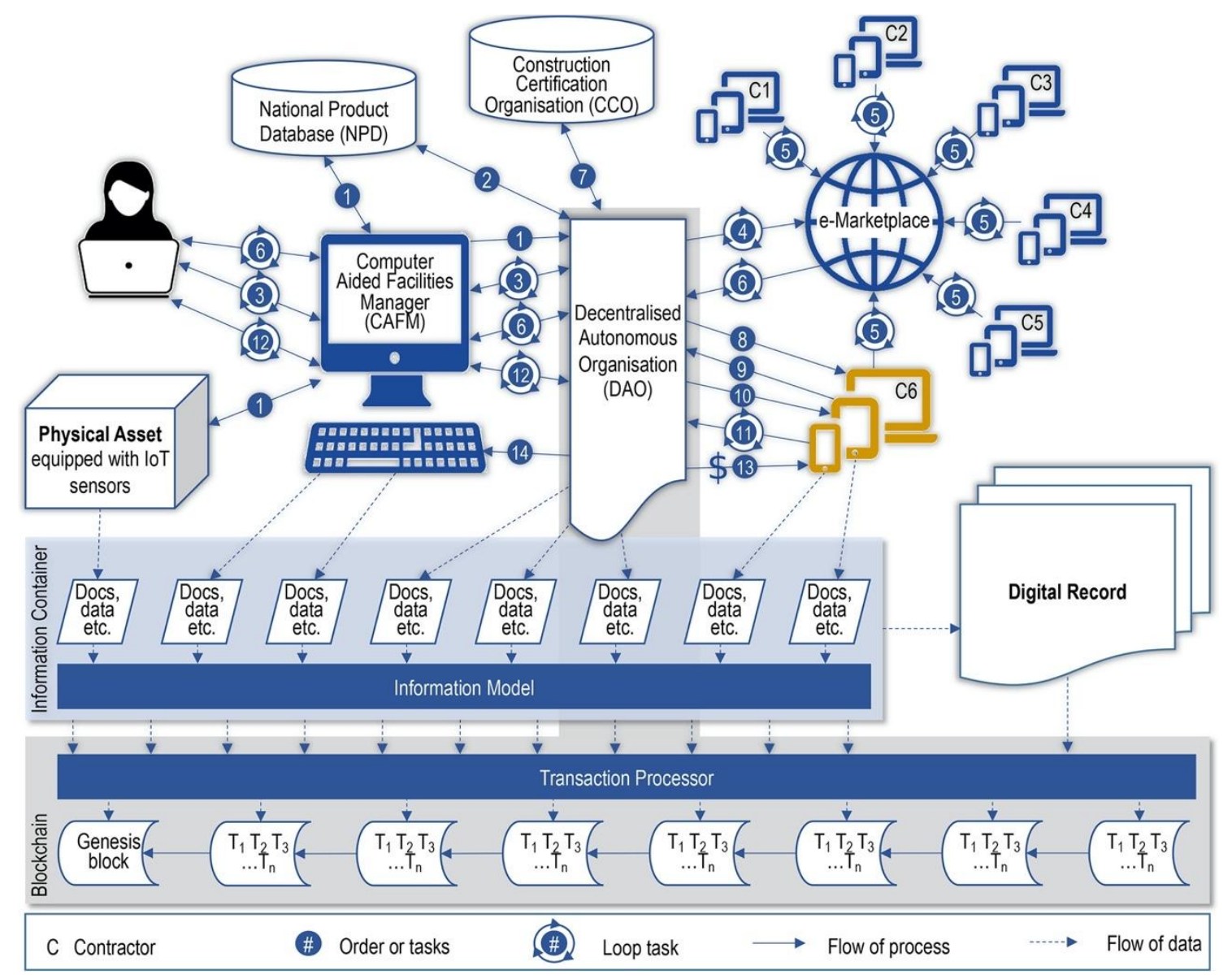

Figure 1. Integration of BIM, IoT, DLT and smart contracts for semi-automating maintenance and repairs during the operation of a built asset

The "Information Container" represents part of the BIM process as set out in ISO 19650 which acts as a central repository of information (e.g. information model, documents, data) for all parties involved in the project to contribute to and/or access dependent on rights access. The "e-Marketplace" is an internet-based platform that allows eprocurement of goods and services, in this instance, for maintenance and repairs. According to Costa and Grilo, e-procurement reduces 3\% of public expenditure, "reduces complexity, improves competitiveness and transparency, and creates an integrated electronic environment to support advanced electronic instruments to manage, and monitor contracts" (Costa and Grilo, 2015, p. 2). Integrating e-procurement into the framework proposed in this paper can support a solution to address the failings identified in the Hackitt Report with the exception of failing 6 around residents' voices being heard.

The proposed National Product Database (NPD) is an entity that holds information about built asset components (e.g. a HVAC unit) such as: product name, classification, manufacturer, date brought to market, date removed from market, unique identifier, compliance certifications (standard, testing body, testing date, certificate number) and product characteristics. Such an entity would ensure that facilities managers have access to the most comprehensive and up-to-date information about a component and would be notified of any changes to the building standards and regulations appropriate to them. This element considers the legislative artefacts discussed in the definition of technological systems in section 2 where specific requirements relate to construction products/components. The organisation managing the NDP would need to ensure the 
information was kept to-to-date by the manufacturer and updated with changes to standards and regulations; the products/components linked to the CAFM system would need to share a unique identifier with those in the NPD ensuring they 'talk the same language' (e.g. they both know they are talking about "fire performance" according to the appropriate international standard). The Government's response to the Hackitt Report includes establishing a Building Safety Regulator and a "new national Construction Products regulatory role" (Ministry of Housing, Communities and Local Government, 2020, p. 12). Automating updates to standards and regulations in the NPD would ensure Facilities Managers remain compliant and can respond quickly to any changes in legislation. Creation of such an NPD supports addressing failing 5 in the Hackitt Report around the requirement for better testing, labelling and marketing of construction products whilst offering readily available traceable information.

The Construction Certification Organisation (CCO) is similar to that of the Construction Skills Certification Scheme (CSCS) (CSCS, 2020) in the UK, which is an organisation that maintains up to date records of the skills and certifications individuals hold and provides those individuals with an ID card that is linked to their account. Automating checks of individual personnel with such an organisation at the procurement phase can be directly linked to ensuring "competence across the system" (failing 4).

The steps taken in the semi-automated process for maintenance and repairs of built assets demonstrate how the technological systems integrate and are illustrated in the flowchart in Figure 2 which correlates to the numbered steps in Figure 1.

Maintenance and repairs can be triggered in one of four ways: via IoT sensors that detect component faults; scheduled maintenance programmed to and notified by the CAFM system; push notifications from the NDP that there is a change to standards and/or regulations; and direct notification to the CAFM system by a human (step 1). Once the maintenance/repair event has been triggered, the DAO will execute by checking with the NPD for any/all updates relating to the components to be maintained/repaired even if the trigger came from the NDP in the first place to cover changes to any other linked components/systems (step 2). The system then requests the tender criteria for the maintenance/repair job via the CAFM system (step 3), for example, time requirements, calibre and competencies of personnel, health and safety requirements, quality assurance, environmental approach and track record along with weighting to score each criterion. The DAO will compile an Invitation to Tender (ITT) request based on a pre-loaded template inputting the tender criteria from step 3 . The ITT is issued automatically to the e-Marketplace by the DAO (step 4). Prospective contractors submit bids via the e-Marketplace to the DAO (step 5). The tender competition is managed by the DAO, which facilitates the bidding process scoring contractors against the tender criteria (step 6). Before a contractor is selected, the DAO will connect with the $\mathrm{CCO}$ to confirm the competency of the contractors meets the tender criteria confirming they are certified to complete the work (step 7). In this instance, the $\mathrm{CCO}$ acts as an oracle providing information that is external to the CAFM system to be processed by a non-deterministic smart contract in the DAO. If a suitable contractor is found, the DAO issues a contract to the winning contractor (conceptualised by C6 in Figure 1) and notifies unsuccessful tenderers of the result (step 8). In the event a suitable contractor is not found based on the initial tender criteria, the DAO will loop back to step 3 and request for a change in tender criteria before repeating the process until a suitable contractor is found. Upon acceptance of the contract by C6 (step 9), the DAO issues a work package order with full details for conducting the work (step 10). 


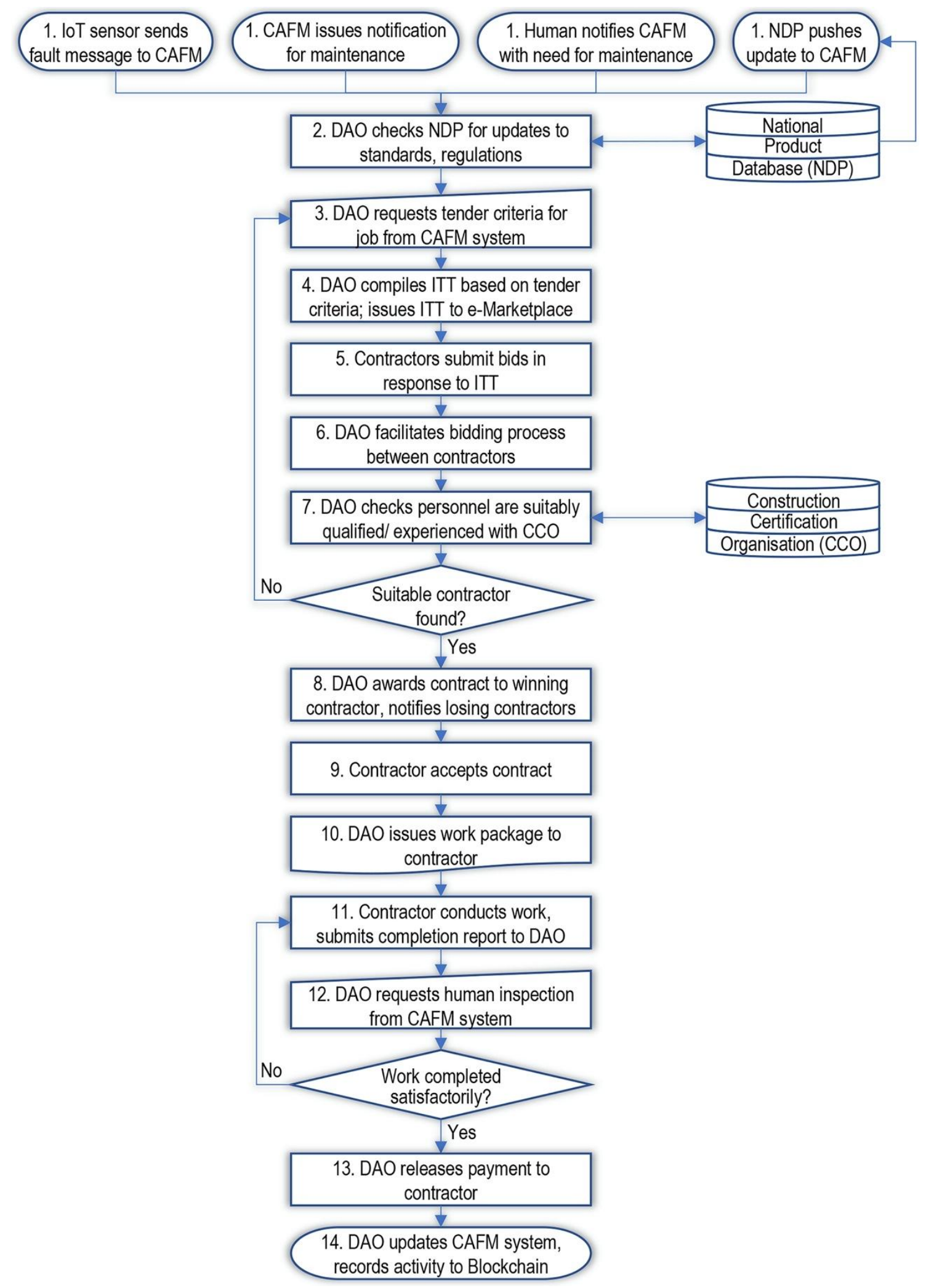

Figure 1. Flowchart explaining the steps taken to semi-automate maintenance and repairs during operation and repairs of built assets

C6 carries out the maintenance and repairs based on the work package instructions. Upon completion, C6 submits a completion report to the DAO (step 11). The completion 
report should contain details of what was done, by whom, to what standards, when, why etc. such that the digital record can be linked to the appropriate information. For example, Asset (ID 123456) was maintained to standard ID XYZ by replacing filter part (type ID 67890, instance ID ABCDEF) with part (type ID 67890, instance ID GHIJK) on 07-04-20XX, by operative (ID $\mathrm{xxxxx}$ ) and tested for compliance using process (ID yyyyyy). The CAFM system will request human inspection where appropriate to confirm the work has been completed satisfactorily (step 12). In the event the work has not been completed satisfactorily, a rework loop begins until human interaction confirms satisfactory completion of the job. Upon confirmation that the work has been completed satisfactorily, the DAO will release payment to C6 (step 13). Finally, the DAO updates the CAFM system with the new status to reflect the changes and records traceability information about the maintenance event to the Blockchain such as that in the example above (step 14).

Throughout the process, data, certifications, schedules etc. are produced by the parties and systems involved. The items are collected in an information container and uploaded to the information model where appropriate. Depending on the requirements and the exchanges of value that take place throughout the process, specific transactions are transferred to the blockchain via a transaction processor. This may be documentation such as proof that asset components meet building regulations, financial transactions upon completion of a job, recording of decisions made during the process etc. The purpose of this is to provide immutable, chronological proof of the chain of activities that take place during the operation of the built asset whilst keeping a live version of the information model throughout the asset lifecycle. Contemporaneously, data, certification and other relevant information about the asset can be linked to the digital record, the requirements of which is to be established by Government working with industry to agree what that information will be (Recommendation 8.2 of the Hackitt Report, p. 104). Items linked to the digital record can be filtered from all information available in the information container for the relevant parties (e.g. regulatory bodies).

\section{DISCUSSION}

The framework proposed in this paper requires a number of changes across the industry for it to become a reality. It proposes the potential application of DLT and smart contracts coupled with existing technologies and processes such as BIM and IoT to revolutionise asset operation and maintenance. A number of aspects for consideration are forthwith discussed.

If the construction sector is to adopt the concept of a decentralised autonomous organisation (DAO), robust governance systems are required. As no one individual is responsible or accountable for the actions of a DAO once it is in operation it is imperative to ensure the smart contracts are coded correctly and vigorously tested before they are enacted (Van Rijmenam and Schweitzer, 2018). Kinnaird and Geipel (2018) state that DAOs "are impervious to conventional regulation as they are stateless" (p. 9). However, this is contrary to van Rijmenan and Schweitzer (2018) who state that, "they must comply with regulatory requirements" (p. 22). They also highlight that this could present a challenge when operating across borders as regulatory systems differ from one state to another. As to whether DAOs can perform better decision making than humans, further research is required. In the context of the framework proposed above, the role of the DAO is to facilitate automation rather than to challenge the regulatory environment in which it operates. However, the DAO can be used as a tool to practise and 
demonstrate compliance with legislation if its instructions are only to execute within the confines of the regulatory system.

The Hackitt Report's recommendation of a mandated digital record requires that it is "open and non-proprietary with proportionate security controls" (Hackitt, 2018, p. 104). To date, the Bitcoin Blockchain protocol is yet to be hacked but there have been successful attacks on Bitcoin exchanges which had weaknesses in their protocols (Skalex, 2017). The framework conceptualises the original Blockchain protocol for its successful history but any system that moves to integrate a distributed ledger should make an assessment of the different options available and consider what is important - privacy, security or speed. No DLT is yet able to offer a high level of privacy, security and speed; typically, one or the other is sacrificed (Allison and Warren, 2019). In addition, the framework does not stipulate between on- or off-chain storage. Currently, "privacy and confidentiality are not guaranteed for on-chain transactions" (Eberhardt and Tai, 2017, p. 2) but future developments in DLT could counteract this state.

The proposed framework moves to address some of the failings in the Hackitt Report highlighted in the introduction but recognises that DLT and smart contracts cannot support solutions to every problem or indeed as standalone systems. Failing 2 expresses ambiguous and inconsistent regulations and guidance and failing 5 is about product testing, labelling and marketing. The underlying failings are about assurance that products meet given levels of performance (e.g. through testing and compliance); that the individuals selecting products have access to appropriate and correct information (e.g. through marketing); and that the correct products are incorporated into the works (e.g. labelling). The Construction Products Regulation (CPR) 2011 (European Commission, 2020) aims to address this for products for which harmonized standards exist, requiring manufacturers to complete a 'declaration of performance' and CE mark for every product. The framework proposes creation of a National Product Database (NDP) that contains information about built asset components from raw materials to manufacturer information. This is an ambitious proposal given the effort required to establish such an entity but, once operational, it could serve as a powerful tool to support the construction sector in meeting regulations and compliance. It would link components to specific pieces of regulation and building standards and push updates when requirements for compliance change or if a product is updated, re-tested, withdrawn from sale or recalled. Each time a component is due to be maintained, the proposed system actively connects with the NDP to check for changes to regulations and standards to enable it to respond quickly and appropriately. But the NDP also pushes notifications to the CAFM system when changes to legislative artefacts are made to allow it to respond outside of scheduled maintenance periods. This way, information is always in line with the most up-to-date source.

In a similar vein, connecting to a Construction Certification Organisation (CCO) such as CSCS will ensure individuals are suitably qualified and experienced to conduct the work for which they are bidding, which addresses failing 4 concerned with competency and, in part, failing 1 concerned with roles and responsibilities. Making the individuals assigned to specific roles along with their responsibilities publicly available will hold them to account and drive establishing clearer responsibilities from the outset by encouraging a change in behaviour (Baucherel, 2020). The use of smart contracts here will drive that clarify, in this instance, through their non-deterministic behaviour and requirement for the $\mathrm{CCO}$ to act as an oracle providing proof of competency.

Establishing an e-procurement system (steps 3 to 7 of the proposed framework) will support addressing failing 3-weaknesses in complying with building safety 
requirements and poor record keeping. Inclusion of computable, machine-readable requirements into tender documents that are then cascaded into appropriate BIM artefacts (e.g. information models) or CAFM systems can be used to run performancebased checks to confirm work has been completed satisfactorily across the built asset lifecycle (Ciribini et al., 2019). Requirements for artefacts linked to the digital record and relevant information to update the CAFM system will be set out during the tender process and automatically administered by the DAO. Translating requirements into computable, performance-based metrics will promote digitisation through automatic generation of digital data that can be processed and transferred and linked to the relevant artefacts (e.g. information container, blockchain, digital record) from the outset.

In addition to addressing a number of the failings identified in the Hackitt Report, there are other benefits to the proposed framework and to automation of activities across the different stages of the built asset lifecycle. While there are many activities that can be automated (e.g. administration tasks, payments), some will not be automated until artificial intelligence is sufficiently advanced to replace the decision-making of humans (e.g. inspections), or until robotics are cost-effective enough to conduct intricate, currently time-consuming work (e.g. maintenance and repairs). Until then, simple, repetitive activities can be automated (Mason, 2017) Further expected benefits in the system include:

- Reduction in human error through automation;

- Reduction in contract administration tasks by facilities managers;

- Increased productivity;

- Automatic generation of digital data in the required format;

- Automation leading to efficiencies in the operation and maintenance of built assets;

- Reduction of transaction costs in the case of cryptocurrencies being used as payment;

- Establishing new markets and business models. The e-Marketplace could extend beyond a single asset so contractors could make offers to more than one organization or tenders from more than one organization could be aggregated. Contractors could automate bids negating the need for them to spend time manually completing bids when they could be carrying out work; and

- Development of trust and track record mechanisms (i.e. introduction of a reputation-based system) for the e-Marketplace.

Considering the current ecosystem in the construction sector, there are a number of barriers to implementation that will likely be resolved over time with technological advancement. They include:

- Limitations on technological capability (e.g. DLT scalability);

- Interoperability between systems (e-Marketplace, CAFM system, blockchain);

- Upfront costs of developing new software and hardware, integrating technological systems, development and promotion of new systems (e.g. NDP, $\mathrm{CCO}$ ), and education and training;

- Digitalisation is required across a number of aspects before systems can be integrated (e.g. procurement, facilities management). 


\section{CONCLUSIONS}

This paper has proposed a forward-thinking framework based on DLT and smart contracts to increase traceability and provide a platform for a digital record conceptualised by the semi-automation of maintenance and repairs during operation of a built asset. The framework conceptualises the establishment of two entities, a National Product Database (NDP) containing data about building components to support facilities managers with compliance with regulations and standards, and the Construction Certification Organisation (CCO) that focuses on ensuring individuals are competent to conduct the work for which they are bidding by providing confirmation that an individual has the skills, qualifications and experience required. In addition, it proposes an e-Marketplace that facilitates e-procurement to reduce complexity, improves competitiveness and transparency, and create an integrated electronic environment to support contract management.

The core aspect of the framework is a DAO that automates many of the activities in maintenance and repair, specifically, the tendering process, management of the contract post-award, facilitating approvals of work complete, facilitating payment of work on completion, and ensuring transfer of data to the information container and the Blockchain, and linking relevant information and documentation with the digital record that increases traceability over and above the current way of working. The system allows for human interaction where required, for example, in adjusting parameters for the tendering process and in approving payment for work complete.

Requirements for fulfilling the digital record are to be established by Government and industry in partnership. However, the framework ensures data produced during the operation of a built asset are collected, processed and stored in line with the requirements established in a BIM project and available on demand with proof and timestamping provided by the blockchain.

The next stage of the research will be to validate the proposed framework with industry practitioners and then test it through simulation of different maintenance activities. In addition, consideration will be given to how to mitigate the barriers to implementation.

\section{REFERENCES}

Allison, N. and Warren, M. (2019) 'Applying Blockchain to product compliance and assurance in the construction industry', BRANZ, Report ER42 [2019]. www.gs1nz.org/assets/Publications/5b412dc915/Blockchain.pdf

Aslam, H.M. and Tarmizi, H.A. (2018) 'Intelligent BIM record model for effective asset management of constructed facility', MATEC Web of Conferences, 195, p. 06004. DOI: $10.1051 /$ matecconf/201819506004.

Barnaghi, P., Wang, W., Henson, C. and Taylor, K. (2020) 'Semantics for the Internet of Things: early progress and back to the future', International Journal on Semantic Web and Information Systems, 8, pp. 1-21. DOI: 10.4018/jswis.2012010101.

Baucherel, K. (2020) Blockchain Hurricane: Origins, Applications and Future of Blockchain and Cryptocurrency. Business Expert Press: New York, NY.

Christiansen, B. (2018) 4 Biggest Building Maintenance Challenges and Solutions, Buildings. Available at: https://www.buildings.com/news/industrynews/articleid/21564/title/building-maintenance-challenges-solutions (accessed: 8 April 2020). 
Ciribini, A.L.C., Bolpagni, M. and Oliveri, E. (2015) 'An Innovative Approach to e-public Tendering Based on Model Checking', Procedia Economics and Finance, 21, pp. 3239. DOI: 10.1016/S2212-5671(15)00147-1.

Clack, C.D., Bakshi, V.A. and Braine, L. (2016) 'Smart Contract Templates: foundations, design landscape and research directions', arxiv, pp. 1-15. arxiv.org/abs/1608.00771.

Costa, A. and Grilo, A. (2015) 'BIM-based e-procurement: An innovative approach to construction e-procurement', The Scientific World Journal, 2015, 905390. DOI: $10.1155 / 2015 / 905390$.

CSCS (2020) The Official site for the Construction Skills Certification Scheme. Available at: https://www.cscs.uk.com (accessed: 6 April 2020).

Eberhardt, J. and Tai, S. (2017) 'On or Off the Blockchain? Insights on Off-Chaining Computation and Data', In: F., D.P., S., S., and E., B.J. (eds.) Service-Oriented and Cloud Computing. ESOCC 2017. Lecture Notes in Computer Science, Springer, Cham, pp. 3-15.

European Commission (2020) Construction Products Regulation (CPR), https://ec.europa.eu/growth/sectors/construction/product-regulation_en.

Farmer, M. (2016) The Farmer Review of the UK Construction Labour Model: Modernise or Die, Construction Leadership Council. www.constructionleadershipcouncil.co.uk/wp-content/uploads/2016/10/FarmerReview.pdf.

FARO (2019) Traceable Construction: FARO's Ecosystem for an Informed Construction Lifecycle. https://insights.faro.com/construction-bim/traceable-construction-faro-secosystem-for-an-informed-construction-lifecycle-brochure.

Ghaffarianhoseini, A., Tookey, J., Ghaffarianhoseini, A., Naismith, N., Azhar, S., Efimova, O. and Raahemifar, K. (2017) 'Building Information Modelling (BIM) uptake: Clear benefits, understanding its implementation, risks and challenges', Renewable and Sustainable Energy Reviews, 75, pp. 1046-1053. DOI: 10.1016/j.rser.2016.11.083.

Hackitt, J. (2018) Building a safer future - Independent Review of Building Regulations and Fire Safety: Interim Report. www.gov.uk/government/uploads/system/uploads/attachment_data/file/668747/Inde pendent_Review_of_Building_Regulations_and_Fire_Safety.pdf.

ISO (2018) ISO 19650-1:2018 Organization and digitization of infomration about buildings and civil engineering works, including building information modelling (BIM) - Information management using building information modelling - Part 1: Concepts and Principles. www.iso.org/standard/68078.html.

Jylhä, T. and Suvanto, M.E. (2015) 'Impacts of poor quality of information in the facility management field', Facilities, 33, pp. 302-319. DOI: 10.1108/F-07-2013-0057.

Katenbayeva, A., Glass, J., Anvuur, A. and Ghumra, S. (2016) 'Developing a theoretical framework of traceability for sustainability in the construction sector', 12th Corporate Responsibility Research Conference, 12-14th October, Istanbul, Turkey. https://dspace.lboro.ac.uk/2134/23842.

Kinnaird, C. and Geipel, M. (2018) Blockchain Technology: How the Inventions Behind Bitcoin are Enabling a Network of Trust for the Built Environment, ARUP. https://www.arup.com/publications/research/section/blockchain-technology.

Kraken IM (2020) Halcyon. Available at: https://www.kraken.im/software/halcyon/ (accessed: 8 April 2020).

Lee, M., Wang, Y.R. and Huang, C.F. (2017) 'Design and implementation of a simple user interface of building construction traceability system', In: Proceedings of the 2017 
IEEE International Conference on Applied System Innovation, ICASI 2017, 13-17 May, Sapporo, Japan, pp. 736-739.

Li, J., Greenwood, D. and Kassem, M. (2019a) 'Blockchain in the built environment and construction industry: A systematic review, conceptual models and practical use cases', Automation in Construction, 102, pp. 288-307. DOI: 10.1016/j.autcon.2019.02.005.

Li, J., Kassem, M., Ciribini, A.L.C. and Bolpagni, M. (2019b) 'A proposed approach integrating DLT, BIM, IOT and smart contracts: Demonstration using a simulated installation task', In: DeJong, M., Schooling, J., and Viggiani, G. (eds.) International Conference on Smart Infrastructure and Construction 2019 (ICSIC): Driving datainformed decision-making, 8-10 July, Cambridge, UK, pp. 275-282. DOI: 10.1680/icsic.64669.275.

Mäki, T. and Kerosuo, H. (2015) 'Site managers' daily work and the uses of building information modelling in construction site management', Construction Management and Economics, 33, pp. 163-175. DOI: 10.1080/01446193.2015.1028953.

Mason, J. (2017) 'Intelligent Contracts and the Construction Industry', Journal of Legal Affairs and Dispute Resolution in Engineering and Construction, 9(3), p. 04517012. DOI: 10.1061/(ASCE)LA.1943-4170.0000233.

Ministry of Housing, Communities and Local Government (2020) A reformed building safety regulatory system: Government response to the 'Building a Safer Future' consultation.

https://assets.publishing.service.gov.uk/government/uploads/system/uploads/attachm ent_data/file/877628/A_reformed_building_safety_regulatory_system_-

_gvt_response_to_the_Building_a_Safer_Future_consultation.pdf.

Morabito, V. (2017) Business Innovation Through Blockchain: The B3 Perspective. Cham: Springer International Publishing.

Naghshbandi, S.N. (2016) 'BIM for Facility Management: Challenges and Research Gaps', Civil Engineering Journal, 2(12), pp. 679-684. DOI: 10.28991/cej-2016-00000067.

Olsen, P. and Borit, M. (2018) 'The components of a food traceability system', Trends Food Science \& Technology, 77, pp. 143-149. DOI: 10.1016/j.tifs.2018.05.004.

Penzes, B. (2018) Blockchain Technology in the Construction industry: Digital Transformation for High Productivity, Institution of Civil Engineers. www.ice.org.uk/ICEDevelopmentWebPortal/media/Documents/News/Blog/Blockcha in-technology-in-Construction-2018-12-17.pdf

Pinti, L., Bonelli, S., Brizzolari, A., Mirarchi, C., Dejaco, M.C. and Kiviniemi, A. (2018) 'Integrated information management for the FM: Building information modelling and database integration for the Italian Public Administration', In: Karlshøj, J. and Scherer, R. (eds.) eWork and eBusiness in Architecture, Engineering and Construction (ECPPM 2018), Taylor \& Francis Group, London, Denmark, Copenhagen pp. 21-28.

Pirbhulal, S., Zhang, H., Alahi, M.E.E., Ghayvat, H., Mukhopadhyay, S.C., Zhang, Y.T. and $\mathrm{Wu}, \mathrm{W}$. (2017) 'A novel secure IoT-based smart home automation system using a wireless sensor network', Sensors, 17(1), pp. 1-19. DOI: 10.3390/s17010069.

Raymond, L. and Bergeron, F. (2008) 'Project management information systems: An empirical study of their impact on project managers and project success', International Journal of Project Management, 26(2), pp.213-220. DOI: 10.1016/j.ijproman.2007.06.002. 
Rice-Oxley, M. (2018) Grenfell: the 72 victims, their lives, loves and losses, The Guardian. Available at: https://www.theguardian.com/uk-news/2018/may/14/grenfell-the-71victims-their-lives-loves-and-losses (accessed: 8 April 2020).

Skalex (2017) How Blockchain Applications Can Be Hacked, And What You Can Do To Prevent It. Available at: https://www.skalex.io/blockchain-applications-hack/ (accessed: 6 April 2020).

Snyder, J., Menard, A. and Spare, N. (2018) Big data = big questions for the engineering and construction industry, FMI. https://www.fminet.com/wpcontent/uploads/2018/11/FMI_BigDataReport.pdf.

Sreckovic, M. and Windsperger, J. (2019) 'Decentralized Autonomous Organizations and Network Design in AEC: a conceptual framework', In: Kumar, B., Rahimian, F., Greenwood, D., and Hartmann, T. (eds.) Proceedings of the 36th CIB W78 2019 Conference, 18-20 September, Newcastle, UK, pp. 842-850. ISBN: 9781861354860.

UK BIM Framework (2020) About Us. Available at: https://ukbimframework.org/about/ (accessed 6 April 2020).

van Dam, K.H. (2009) 'Capturing socio-technical systems with agent-based modelling', TU Delft. https://repository.tudelft.nl/islandora/object/uuid:1b36bc02-c7fe-47739ab2-3daa3b891754.

Van Rijmenam, M. and Schweitzer, J. (2018) A Distributed Future: Where Blockchain Technology Meets Organisational Design and Decision-making. https://www.researchgate.net/publication/319059647_A_Distributed_Future_Where_ Blockchain_Technology_Meets_Organisational_Design_and_Decision-making.

Watson, R., Kassem, M. and Li, J. (2019) 'Traceability for built assets: Proposed framework for a Digital Record', In: Skibniewski, M.J. and Hajdu, M. (eds.) Proceedings of the Creative Construction Conference (2019), 068. pp. 496-501. Diamond Congress Ltd., Budapest (2019).

Woodhead, R., Stephenson, P. and Morrey, D. (2018) 'Digital construction: From point solutions to IoT ecosystem', Automation in Construction, 93, pp. 35-46. DOI: 10.1016/j.autcon.2018.05.004. 